\title{
Geomagnetic Signature of the Total Solar Eclipse of 29 March 2006 Over Africa and the Comprehensive Model Prediction
}

\author{
Elvis V Onovughe \\ Department of Earth Sciences, Federal University of Petroleum Resources, Effurun, Delta State, Nigeria \\ Earth \& Ocean Sciences, School of Environmental Sciences, University of Liverpool, Liverpool L69 3GP, United Kingdom \\ *Corresponding Author:Elvis.Onovughe@liv.ac.uk
}

Copyright (C) 2013 Horizon Research Publishing All rights reserved.

\begin{abstract}
Minute values of all three geomagnetic field components X, Y, Z (north-south, east-west and vertically downward components respectively) were taken from four observatories in Africa (Bangui, Mbour and Tamarraset) and South Atlantic (Ascension Island) during the total solar eclipse and analysed. Results were compared with the Comprehensive Model (CM4) to see whether the model was able to reasonably predict the observatory data during the eclipse - or does the modification of the geomagnetic field at ground level as a result of the ionosphere being shielded from the Sun's heating and ionization radiation during the eclipse provides constraints for the model? Results show pronounced eclipse feature at Tamarraset, with a decrease of about $20 \mathrm{nT}$ in X component and an increase of $5 \mathrm{nT}$ in $\mathrm{Y}$ component. The model was also able to reasonably predict the observatory data at Tamarraset - doing very well in $\mathrm{Y}$ and $\mathrm{Z}$ components compared to $\mathrm{X}$. No significant effect was noticed in Bangui, Mbour and Ascension Island. The model did a fairly good job predicting the data at Bangui and Mbour but not so well at Ascension Island
\end{abstract}

Keywords Geomagnetic Field Components, Total Solar Eclipse, Comprehensive Model, CM4

\section{Introduction}

It has long been observed that solar eclipse may results in significant effect on the geomagnetic field at the Earth's surface [1-3]. This may results in various local effects on the geomagnetic field components at ground level. Solar eclipse alters the ionospheric E-region process and as a result affects the regular geomagnetic daily variation $(\mathrm{Sq})$. The ionospheric effects during a solar eclipse depends on several factors such as the level of solar activity, level of geomagnetic disturbance, geophysical conditions, geographical latitude and longitude, and the local time [4]. It was recognised long ago that during a solar eclipse part of the ionosphere is shielded from the Sun's heating and ionization radiation (the part in the penumbra is partially shielded). As a result the current pattern in this region is expected to be modified which is in turn detectable as a modification to the geomagnetic field observed at ground level [5].

Even though previous studies have shown the clear and sometimes significant effects of solar eclipse on the geomagnetic field observed on ground level, the measurements and results have more or less be conflicting making it somehow confusing. Momani et al [6] in their study of the 2003 total solar eclipse over Antarctica showed a pronounced decrease in the north-south (X) component of the magnetic field with no significant effect in the east-west $(\mathrm{Y})$ and vertical $(\mathrm{Z})$ components. They suggested that the decrease in the $\mathrm{X}$ component was consistent with the depletion in the ionospheric total electron content. Ladynin et al [7] observed a decrease in the $X$ component and an increase in the Inclination I during the 1 August 2008 total solar eclipse. They also reported that data analysis on the eclipse of August 11, 1999 in Europe failed to unambiguously reveal eclipse effects. On their part, Ozcan and Aydogdu [2]reported no effect on the X component of the geomagnetic field during the 11 August 1999 total solar eclipse over Turkey, but a significant decrease in the Y component of the geomagnetic field. They also suggested that a reduction in the ionospheric electron density during the eclipse may have caused a modification of the geomagnetic field at ground level. Malin et al. [8] reported a significant increase in the $\mathrm{D}(\mathrm{Y})$ component of the geomagnetic field during the 11 August 1999 total solar eclipse at Elazing and Kandilli in Turkey. While Nevanlinna and Hakkinen [3] observed a decrease in the $\mathrm{X}, \mathrm{Y}$, and $\mathrm{Z}$ components of the geomagnetic field during the July 221990 solar eclipse in Finland.

This present study looks at the effects of the total eclipse of 29 March 2006 on the geomagnetic diurnal variation field 
and compares the signature of the geomagnetic field components with existing models, particularly the Comprehensive Model (CM4) [9]. Can the CM4 reasonably predict theground variations of the geomagnetic field during period of eclipse or does the modification of the geomagnetic field at ground level as a result of part of the ionosphere being shielded from the sun's heating and ionization radiation during the eclipse provides constraints?

\subsection{The Comprehensive Model [9]}

The Comprehensive Model is a comprehensive long wavelength and long time span magnetic field model based on observatory and satellite data, generating primary and induced components of both internal (core and lithospheric) and external (magnetospheric and ionospheric) fields. The current version is called Comprehensive Model 4 (CM4) developed by Terry Sabaka of Raytheon ITSS/NASA and Nils Olsen of the Danish Space Research Institute. The model is not considered predictive, since the parameterisation relies on input of known data such as magnetic indices; however many of the daily variations are consistent over long periods of time, so can be used as guide. The model works better in times where the magnetic indices are having less of an effect on the model results, which is lower magnetic activity periods, but the general fit of the model to data begins to decrease with higher magnetic activity. The external fields component of CM4 is applicable presently only or restricted to magnetically quiet conditions/periods (roughly $\mathrm{Kp} \leq 2$ ).

\section{Geophysical Location of the 2006 Total Solar Eclipse}

The total solar eclipse took place on a Wednesday $29^{\text {th }}$ March 2006 and was visible within a narrow corridor traversing half of planet Earth. The path of the total solar eclipse and the zones of the partial eclipse through Africa are shown in Figure 1. The path of the totality of the Moon's umbra shadow began at sunrise (08.36UT) in eastern Brazil. It had a wide path of $129 \mathrm{~km}$ from the centre with duration of $1 \mathrm{~min} 53 \mathrm{secs}$. Travelling at over $9 \mathrm{~km} / \mathrm{s}$ it races across the Atlantic Ocean, crossing the equator and the Gulf of Guinea, the shadow reached the coast of Africa (Ghana) at 09.08UT. The path width expanded to about $184 \mathrm{~km}$, with the shadow ground speed decreasing to about $0.958 \mathrm{~km} / \mathrm{s}$. The path of totality of the Moon's shadow moved inland, travelling across Ghana, Togo, Benin, Nigeria, Niger, Chad and Libya. The umbra enters Togo at 09.14UT; two minutes later it reached Benin and enters Nigeria at about 09.21UT. The central duration at this point increased to $3 \mathrm{~min} 40 \mathrm{secs}$, with the Sun's altitude $52^{\circ}$ and path of totality $188 \mathrm{~km}$ wide with a velocity of $0.818 \mathrm{~km}$. The umbra moving north traverses through Niger and briefly enters north western Chad before crossing into southern Libya.

The maximum eclipse occurred at about 10:11:18UT when the Moon's axis passes closest to the centre of Earth.

The totality reaches its maximum duration of $4 \mathrm{mins} 7 \mathrm{secs}$ with the Sun's altitude $67^{\circ}$, the path width $184 \mathrm{~km}$ and the umbra's velocity $0.697 \mathrm{~km} / \mathrm{s}$. The umbra crosses central Libya and reaches the Mediterranean coast at 10.40UT, clipping a small corner of northwest Egypt, where the central duration was $3 \mathrm{~min} 58 \mathrm{secs}$. It then crossed into Greece, passing through Turkey, Georgia, Russia, Kazakhstan to Mongolia, before lifting off Earth's surface at 11:48UT (Sunset in Mongolia) [10].

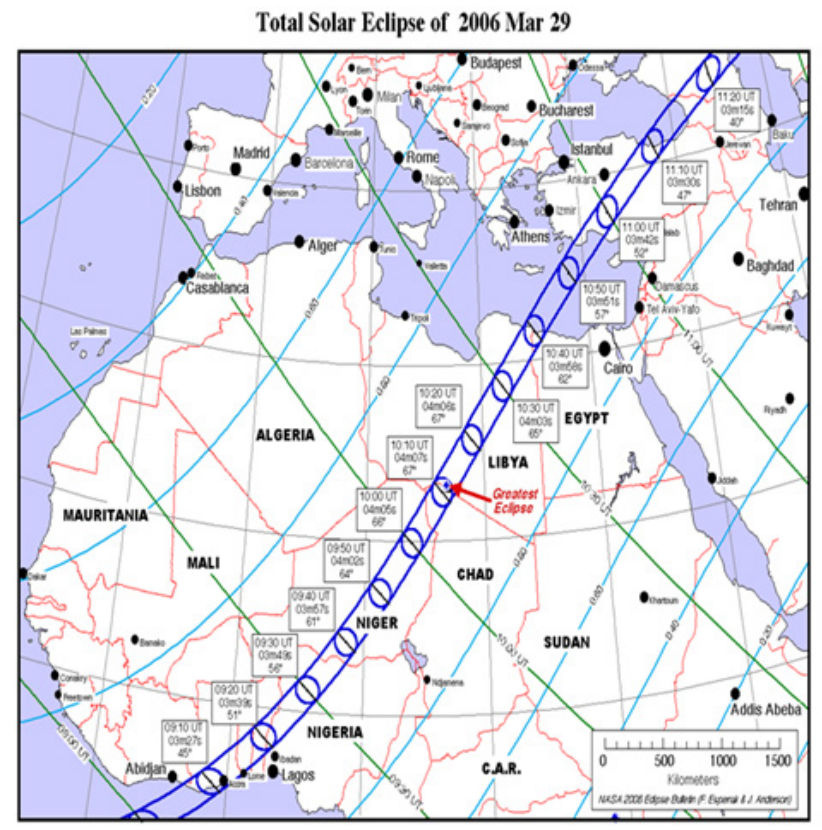

Figure 1. Path of the Total Solar Eclipse on March 29th, 2006 through Africa (Espenak and Anderson 2006)

\section{Materials and Methods}

The geomagnetic field observed at ground surface is typically expressed in geodetic coordinate system. While the magnetic elements $\mathrm{Z}, \mathrm{Y}, \mathrm{Z}$ are the components of the field vector $\mathrm{B}$ in an orthogonal right-handed coordinate system; where $\mathrm{X}$ indicates geographic North component, $\mathrm{Y}$ the geographic East component and $\mathrm{Z}$ vertically down component. The derived magnetic elements are the Declination, D (angle between geographic North and the horizontal direction in which a compass needle is pointing) and Inclination, I (angle between the local horizontal plane and the field vector). Declination, inclination and total intensity can be computed from the orthogonal components using the equations:

$$
\begin{gathered}
\mathrm{D}=\arctan \frac{Y}{X}, \mathrm{I}=\arctan \frac{Z}{H} \\
\mathrm{~F}=\sqrt{H^{2}+Z^{2}}
\end{gathered}
$$

Where $\mathrm{H}$ is given by: $\mathrm{H}=\sqrt{X^{2}+Y^{2}}$

Making the total intensity, $\mathrm{F}: \mathrm{F}=\sqrt{X+Y+X}$

In this study minutes values of $\mathrm{X}, \mathrm{Y}, \mathrm{Z}$ components from 
INTERMAGNET standard observatories (a set of magnetic observatories that meet exacting standards and make their data available through international centres websites within a few days of observation) from Africa (Bangui, BNG; Mbour, MBO and Tamarraset, TAM) and South Atlantic (Ascension Island, ASC) was employed. The data was taken from a day before the eclipse $\left(28^{\text {th }}\right.$ March $)$, on the day of the eclipse $\left(29^{\text {th }}\right.$ March) and a day after the eclipse ( $30^{\text {th }}$ March). Ascension Island and Tamarraset are located along the eclipse path with Bangui and Mbour also getting a bit of the partial eclipse. Table 1 gives a summary of the observatories employed, their coordinates, timing and magnitude of the eclipse in each observatory. The eclipse benefitted from low geomagnetic activity. This is rather important because higher magnetic activity or geomagnetic storm may corrupt and makes it problematic detecting the ionospheric response to the solar eclipse and the general fit of the model begins to decrease.

The study made use of a variation of example 2 of the CM4 which calculates the external and induced fields at half hourly intervals. The table of coefficients and magnetic indices of the model only run up to mid-2002; as a result I had the table and codes updated by adding more recent magnetospheric and ionospheric data (Dst and F10.7) to make it applicable to 2006 when the eclipse took place. This makes it possible for the external and induced fields to be calculated - not including the large portion of the field due to the Earth's core. This effectively removes a baseline value so that the diurnal variation can be seen. The code produces $X$, $\mathrm{Y}$, and $\mathrm{Z}$ components of the overall field making it possible to compare what is happening with the different components and see how well or not the model fits the observatory data.

Table 1. The observaory stations, coordinates, and timing of the solar eclipse of March 29th, 2006 at Bangui (BNG), Mbour (MBO), Tamarraset (TAM) and Ascension Island (ASC).

$\begin{array}{cccccc}\begin{array}{c}\text { Statio } \\ \mathrm{n}\end{array} & \text { Lat } & \text { Long } & \begin{array}{c}\text { Max } \\ \text { Obscuration }\end{array} & \begin{array}{c}\text { Eclipse } \\ \text { Starts }\end{array} & \begin{array}{c}\text { Eclipse } \\ \text { Ends }\end{array} \\ \text { BNG } & 4.3 & 18.6 & 50.46 \% & 08: 23: 32 & 10: 52: 00 \\ \text { MBO } & 14.4 & 343 & 50.06 \% & 08: 10: 17 & 10: 12: 50 \\ \text { TAM } & 22.8 & 5.53 & 75.22 \% & 08: 38: 50 & 11: 11: 44 \\ \text { ASC } & 7.94 & 345 & 81.9 \% & 07: 39: 33 & 09: 46: 54\end{array}$

\section{Results \& Discussion}

Geomagnetic diurnal variation data obtained from four INTERMAGNET standard geomagnetic observatories (ASC, $\mathrm{BNG}, \mathrm{MBO}$ and TAM) were analysed. All the observatories reports $\mathrm{X}, \mathrm{Y}, \mathrm{Z}$ observables and they were examined for geomagnetic field disturbances during the total solar eclipse of $29^{\text {th }}$ march, 2006, largely, over Africa. They were also compared against the Comprehensive Model (CM4) to see if the model was able to predict the geomagnetic signature of the observatory data during the solar eclipse. The results for the different observatories are shown in figures 2, 3, 4 and 5.
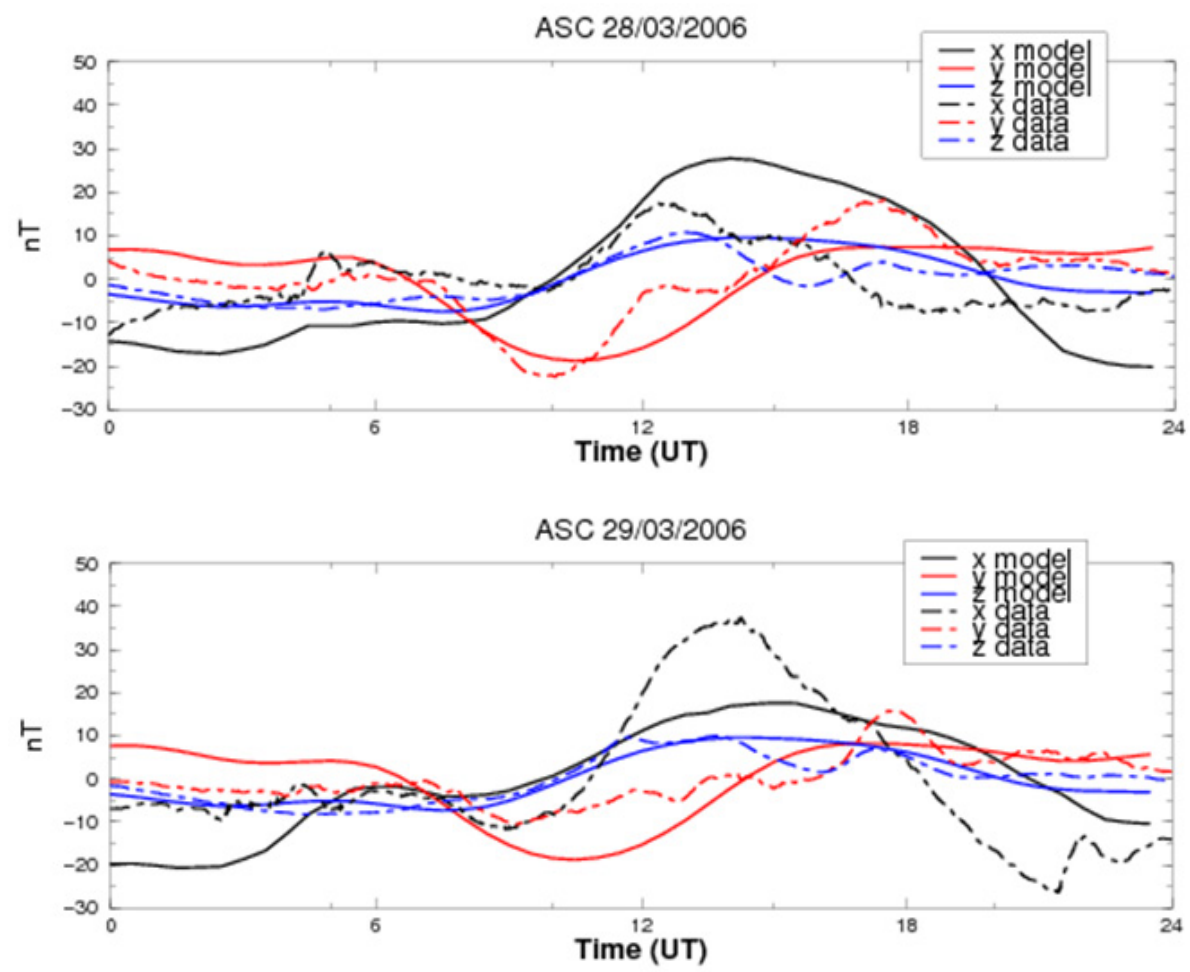


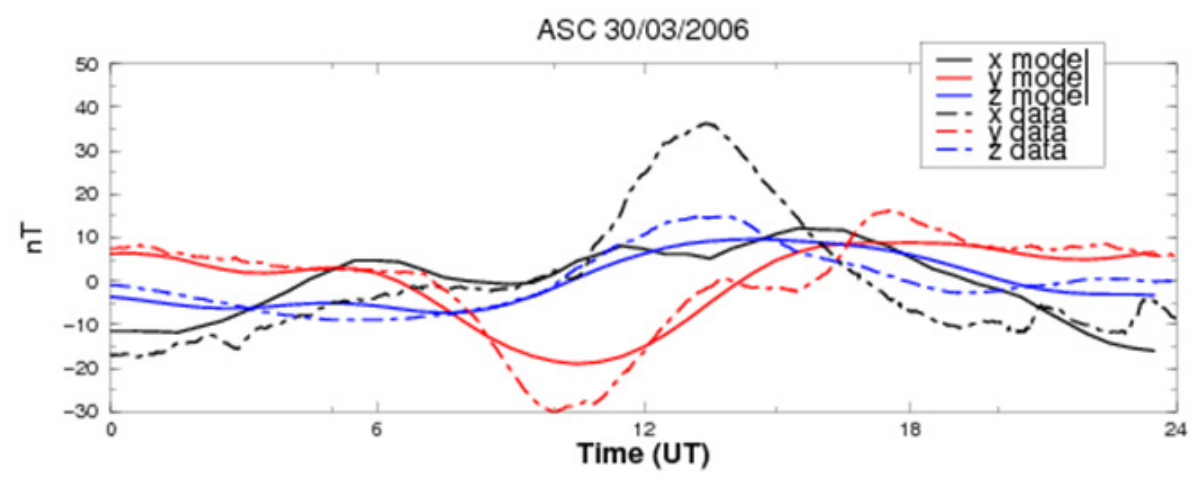

Figure 2. A comparison of the geomagnetic field components at Ascension Island (ASC) and the model (CM4) during the time of the eclipse.
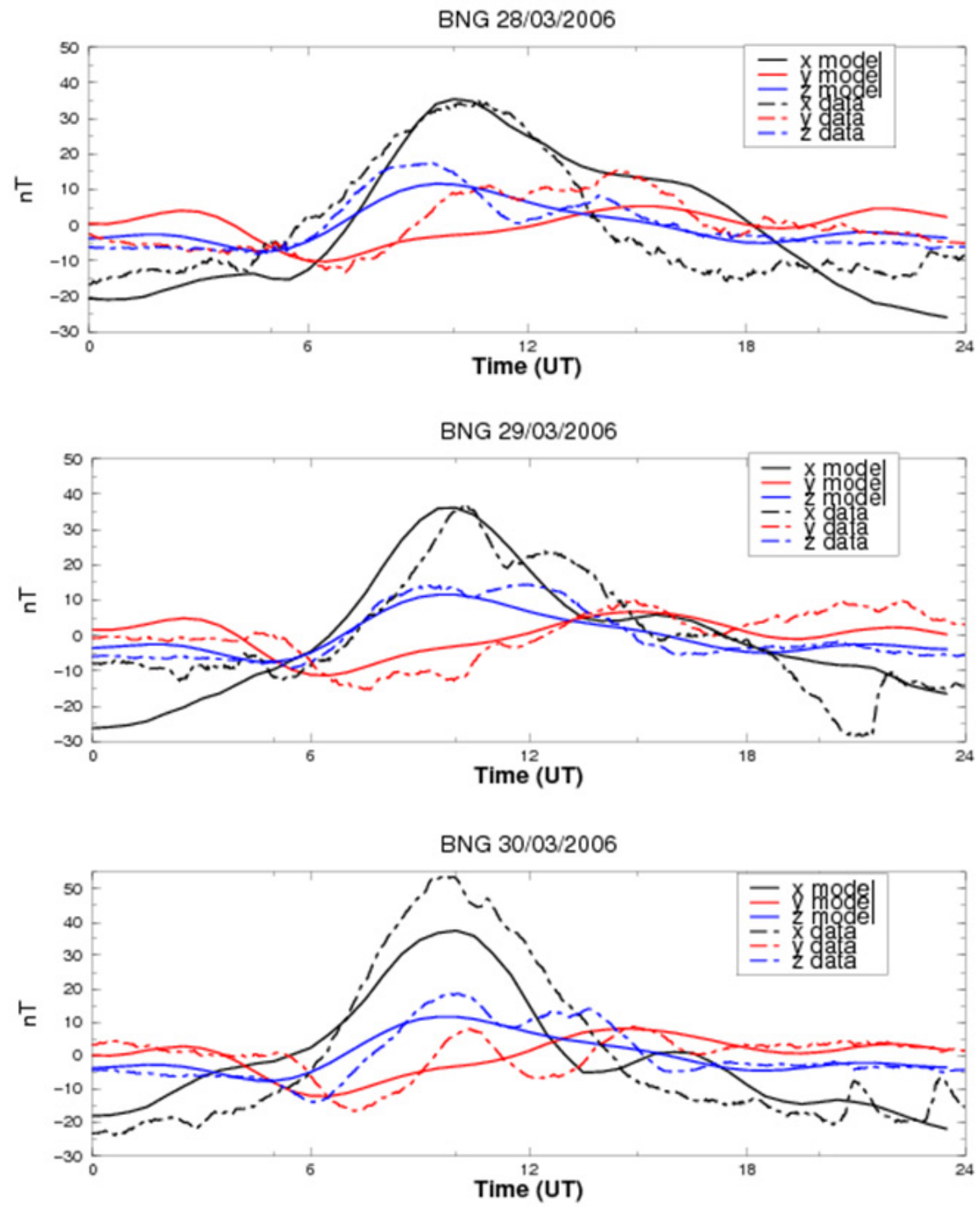

Figure 3. A comparison of the geomagnetic field components at Bangui (BNG) and the model (CM4) during the time of the eclipse. 

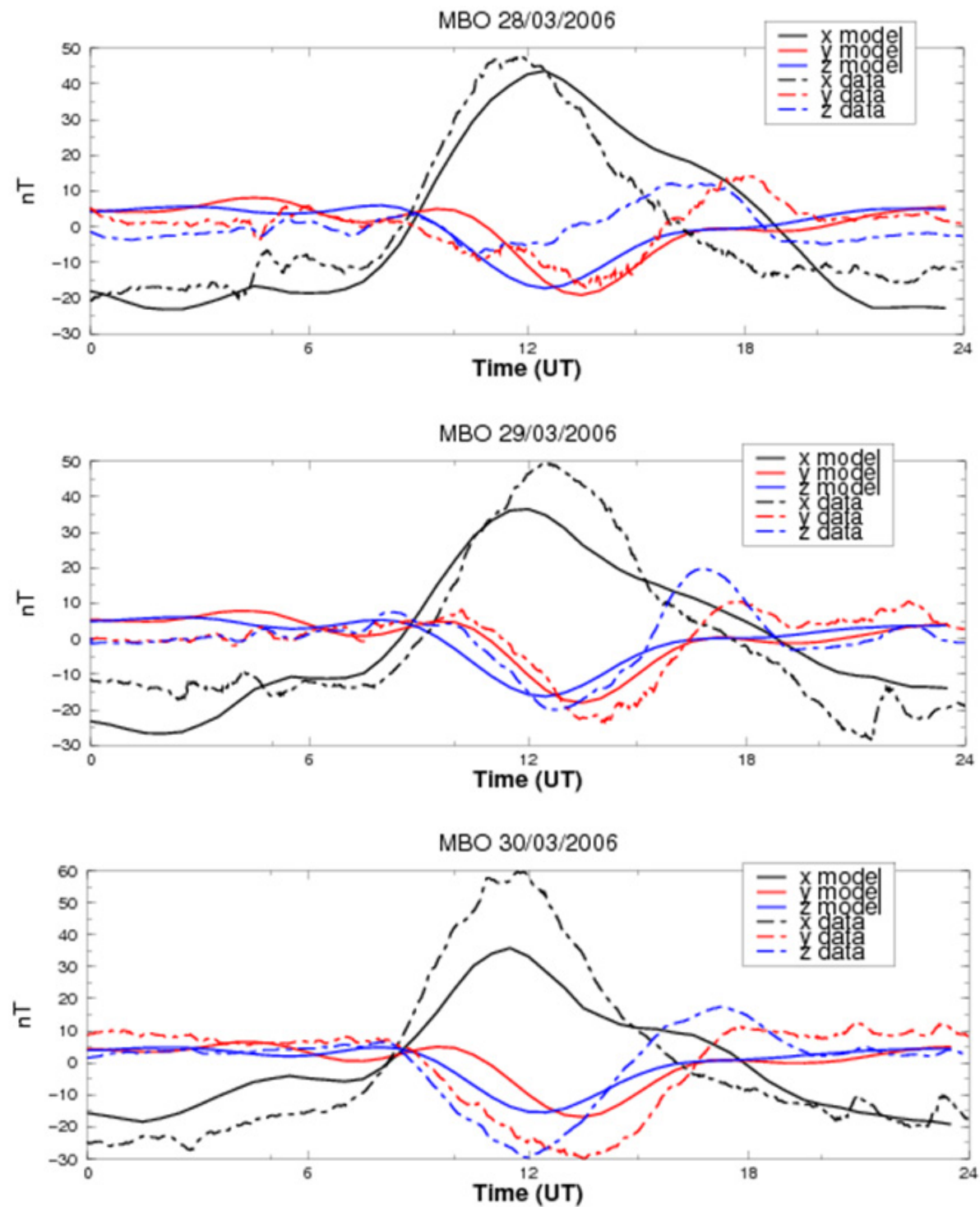

Figure 4. A comparison of the geomagnetic field components at Mbour (MBO) and the model (CM4) during the time of the eclipse.

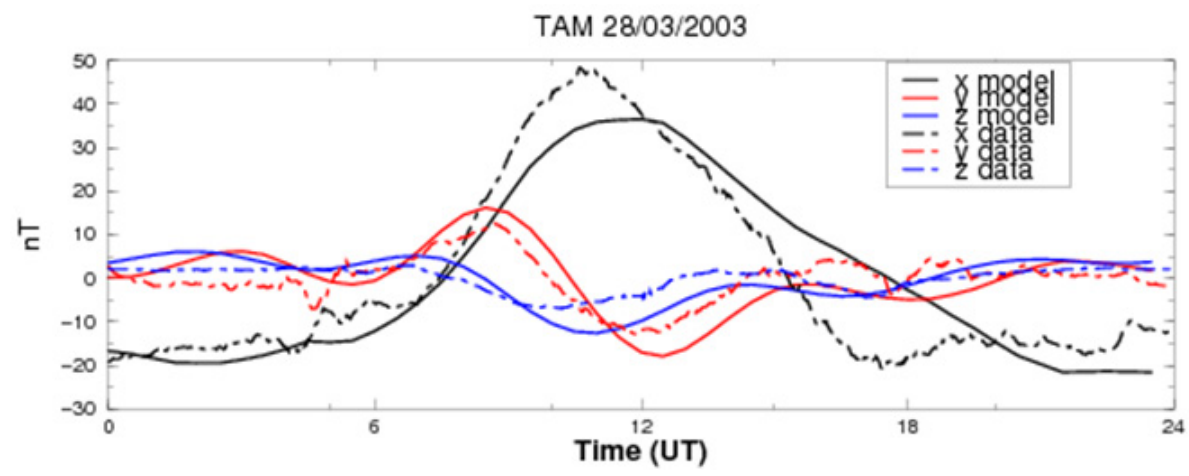



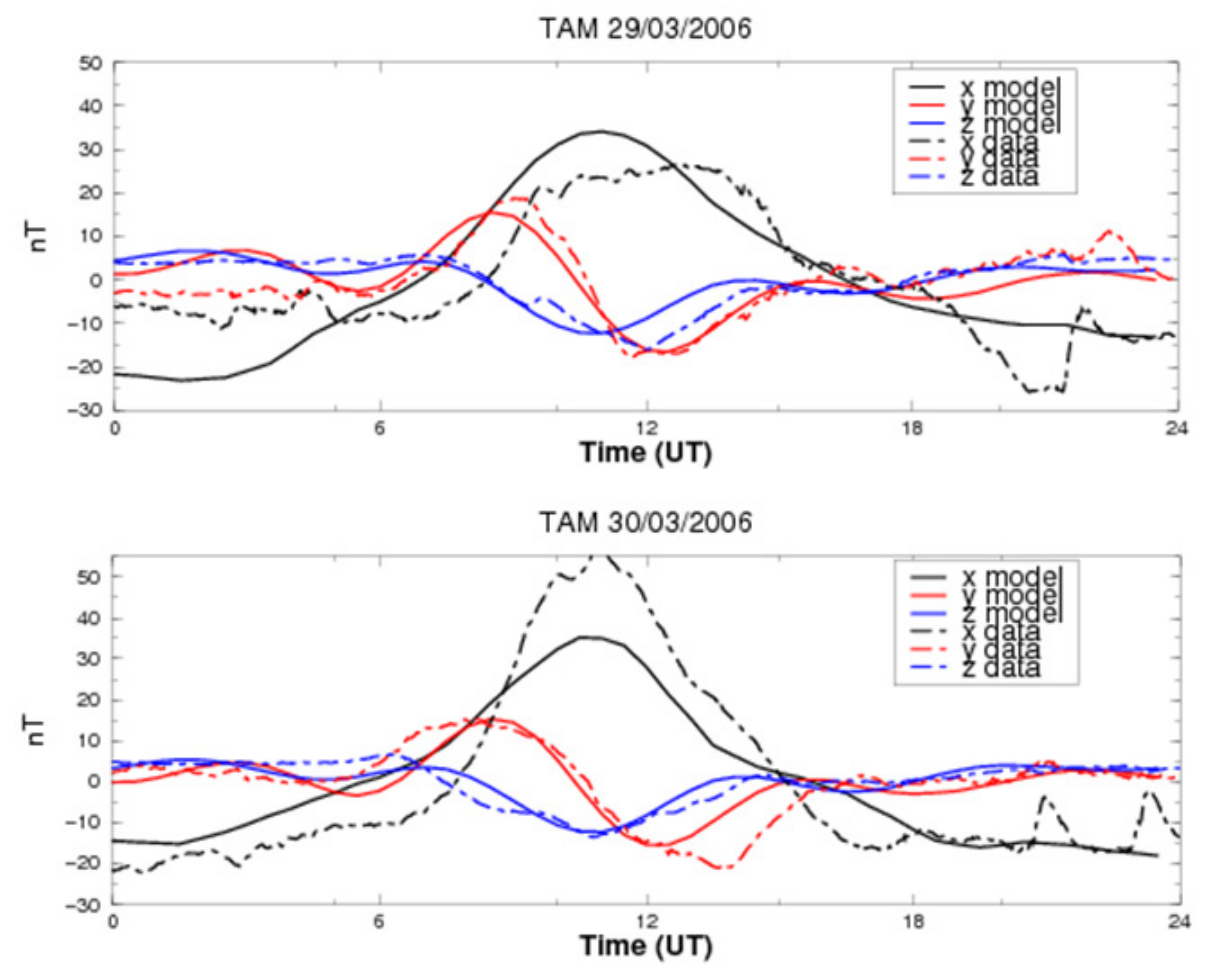

Figure 5. A comparison of the geomagnetic field components at Mbour (MBO) and the model (CM4) during the time of the eclipse.

\subsection{Signature of XYZ Components of Geomagnetic Field} in Ascension Island (ASC) During the Solar Eclipse

Figure 2 shows the results for ASC before, during, and after the eclipse. As can be seen in table 1, ASC experienced a large amount of the partial solar eclipse as seen in its maximum obscuration of about $82 \%$. An increase of about $20 \mathrm{nT}$ is seen in X component on the day $\left.29^{\text {th }}\right)$ of the eclipse compared to the previous day $\left(28^{\text {th }}\right)$. This increase can still be seen a day after $\left(30^{\text {th }}\right)$. A decrease just before noon is observed a day either side of the day of the eclipse. But no discernible change seen in $\mathrm{Z}$ component.

The model did not do enough fitting the data in the $\mathrm{X}$ component, but we can see a reasonable fit between the model and data in $\mathrm{Y}$ and $\mathrm{Z}$ components. The inability of the model to do well fitting the data, especially in $\mathrm{X}$ component, may have nothing to do with the eclipse phenomenon, but other factors open to investigation. This is more so as the eclipse benefitted from low geomagneticactivity and the model is designed to work well under such conditions.

\subsection{Signature of XYZ Components of Geomagnetic Field in Bangui (BNG) During the Solar Eclipse}

The results of the geomagnetic field XYZ components for Bangui before, during and after the eclipse are shown in figure 3. Bangui experienced a partial eclipse of maximum obscuration of about $50.5 \%$. Close analysis shows no significant increase or decrease in XYZ components on the day of the eclipse and the day before which can be adduced to the eclipse effect. The sudden decrease in X component just before noon on the eclipse day $\left(29^{\text {th }}\right)$ may not be due to the eclipse effect as the eclipse start and end time in Bangui (08:23:32UT and 10:52:00UT) was past the time of the decrease. The increase in $X$ component on the $30^{\text {th }}$, a day after the eclipse, maybe due to regular geomagnetic diurnal variation.

The signature of the geomagnetic field for Bangui shows reasonable good fit between the model and data in all the components, with the $\mathrm{X}$ component doing fairly better, especially between the morning and afternoon hours. Again, no eclipse effect in the behaviour or relationship between the model and data.

\subsection{Signature of XYZ Components of Geomagnetic Field in Mbour (MBO) During the Solar Eclipse}

The geomagnetic signature for Mbour (MBO) during the total solar eclipse is shown in figure 4. Mbour saw a partial eclipse of maximum obscuration $50 \%$, the lowest of all the observatories studied. Results show no increase or decrease in signature in all the geomagnetic components (XYZ).

Results also show remarkable good correlation/fit between model and data, especially in Y component.

\subsection{Signature of XYZ Components of Geomagnetic Field in Tamarraset (TAM) During the Solar Eclipse}

Signature measurements for the geomagnetic field components, $\mathrm{XYZ}$ for Tamarraset (TAM) is shown in figure 5. TAM like ASC experienced a large maximum obscuration of the eclipse (75.22\%). Tamarraset's located is also closest 
to the point of the greatest phase of the eclipse. So it is expected to show, more than the others, any eclipse induced effects in the signature of the geomagnetic field components, $\mathrm{XYZ}$ during the eclipse period.

Results show a decrease in X components of about 20nT on the $29^{\text {th }}$, the day of the eclipse, compared to the day before and the day after. The decrease in X component started at about 10:00UT, just before the totality of the eclipse reaches its maximum at about 10:11:18UT. Also observed is a slight increase of about $5 \mathrm{nT}$ on the day of the eclipse compared to the previous day and the day after in $\mathrm{Y}$ component. $\mathrm{Z}$ component shows no significant difference (increase or decrease) during the period of the eclipse, before or after. In the plots we can see a remarkable good fit between the model and data, especially in $\mathrm{Y}$ and $\mathrm{Z}$ components.

\section{Conclusion}

The signature of the geomagnetic field components during the total solar eclipse shows that the feature seen in the total solar eclipse in Tamarraset is an eclipse feature. It shows a feature in the $\mathrm{X}$ and. It shows a feature in the $\mathrm{X}$ and $\mathrm{Y}$ components which agrees with those described by Strestik [1], showing a pronounced decrease in $\mathrm{X}$ component and an increase in $\mathrm{Y}$ component. None of the other observatories shows similar features. Ascension Island which, like Tamarraset, experienced a large maximum obscuration of the eclipse shows a feature in $\mathrm{X}$ and $\mathrm{Y}$ components opposite that of Tamarraset. In Tamarraset, the decrease in the $\mathrm{X}$ component started just before the eclipse reaches its maximum.

The model - data fitness is also better in Tamarraset than the other observatories. Analysis of more data from other observatories within and outside eclipse zone during solar eclipses will need to be studied for more detailed understanding of eclipse effect - and to see how the data perform against the model during eclipses.

\section{Acknowledgements}

My appreciation to INTERMAGNET and ISGI for providing high quality data and indices through their websites: http://www.intermagnet.org and http://www.isgi.c etp.ipsl.fr

\section{REFERENCES}

[1] eclipse on the geomagnetic field, Contrib. Geophys. Geod., 31(1), 331, 2001.

[2] O. Ozcan, M.Aydogdu.Possible effects of the total solar eclipse of August 11, 1999 on the geomagnetic field variations over Elazig-Turkey, J. Atmos. Terr. Phys., 66, 997-1000, 2004.

[3] H. Nevanlinna, LHakkinen. Geomagnetic effect of the total solar eclipse on 22 July 1990, J. Geomagn. Geoelectr.Jpn, 43, 319-321, 1991.

[4] L.W. Baran, I. Ephishov, I.I.Shagimuratov,V.P. Ivanov, A.F. Lagovsky.The response of the ionospheric total electron content to the solar eclipse on August 11, 1999, Adv. Space Res., 31(4), 989-994, 2003.

[5] S. Chapman and J. Bartels. Geomagnetism, Claredon Press, Oxford, UK (1940)

[6] M.A. Momani, T.A. Al Smadi, F.M. Al Taweel, K.A. Ghaidan. Magnetic field disturbances during the 2003 total solar eclipse over Antarctica as observed by magnetometers, Euro. J. of Tech. \& Adv. Engr. Res., ISSN: 1433-2248 (2), 69-75, 2011.

[7] A.V. Ladynin, N.N.Semakov, S.Yu.Khomutov. Changes in the daily geomagnetic variation during the total solar eclipse of 1 August 2008, Russ. Geol. \&Geophys., 52(3), 343-352, 2011.

[8] S.R.C. Malin, O. Ozcan,S.B. Tank, M.K.Tuncer, O. Yazici-Cakin. Geomagnetic signature of the 1999 August 11 total eclipse, Geophys. J. Int., 140, F13-F16, 2000.

[9] T.J. Sabaka, N. Olsen, M.E. Purucker. Extending comprehensive models of the Earth's magnetic field with Orsted and CHAMP data, Geophys. J. Int., 159, 521-547, 2004

[10] F. Espenak, J. Anderson. Total Solar Eclipse of 2006 March 29, http//eclipse.gsfc.nasa.gov/SEpubs/20060329/TP212762 b.pdf 